\title{
PENGARUH JARAK TANAM DAN DOSIS PUPUK KANDANG TERHADAP PERTUMBUHAN DAN HASIL TANAMAN BAWANG MERAH (Allium ascalonicum L.)
}

\author{
Risqan Fitrah Manik ${ }^{1 *}$, Nurhayati ${ }^{1)}$, Erida Nurahmi ${ }^{1)}$ \\ ${ }^{1}$ Program Studi Agroteknologi, Fakultas Pertanian, Universitas Syiah Kuala \\ *Email korenpondensi : risqan@yahoo.com
}

\begin{abstract}
Effect of Plant Spacing and Dosage Manure on Growth and Yield of Shallots (Allium ascalonicum L.). This study aims to determine the effect of plant spacing and doses of manure is right for the growth and yield of onion maximum. This research was conducted at the Agricultural Research Station, substations Organic Horticulture Darussalam, Banda Aceh. This research has been conducted on the month in March 2016 to May 2016. This study used a randomized block design (RAK) factorial $2 \times 4$ with three replications, so that there are 8 combined treatments and 24 experimental units. Factors studied were plant spacing which consists of two levels ie $(20 \mathrm{~cm} \times 15 \mathrm{~cm})$ and $(20 \mathrm{~cm} \times 25 \mathrm{~cm})$ and the dose of manure which consists of four levels ie (without manure), (10 ton ha-1), (20 ton ha-1) and (30 ton ha-1). The results showed that the spacing of significant effect on the wet weight berangkasan per plot and the dry weight of tuber per plot, plant height significantly affected the age of $30 \mathrm{HST}$ and berangkasan dry weight per plot. Influential no significant effect on plant height at 15 and 45 days after planting, leaf number aged 15, 30 and 45 days after planting, the number of tillers per hill, tuber number per hill, wet weight berangkasan per clump, dry weight berangkasan per clump, dry weight of tuber per hill. Growth and the best results encountered at a spacing of 15 $\mathrm{cm} \times 20 \mathrm{~cm}$. Dose manure no real effect on all the observed variables. There was no significant interaction between treatment and dose spacing of manure, so there is no relationship between the two factors.
\end{abstract}

Keywords : onion, plant spacing and doses of manure

\section{PENDAHULUAN}

Bawang merah (Allium ascalonicum L.) merupakan salah satu komoditas sayuran unggulan yang sejak lama telah dibudidayakan oleh petani secara intensif (Sumarni dan Hidayat, 2005). Di Indonesia, bawang merah berkembang dan diusahakan petani mulai di dataran rendah sampai dataran tinggi. Berbagai varietas bawang merah yang diusahakan petani diantaranya adalah Bangkok, Bima, Engkel, Philipines dan Thailand. Salah satu varietas yang telah lama dikenal dan dibudidayakan oleh petani adalah varietas Bima. Produksi varietas ini dapat mencapai 9,9 ton ha-1 (Putrasamedja dan Suwandi, 1996), serta varietas ini cocok ditanam pada musim hujan, serta umur tanam relatif singkat antara 60-65 hari (Wibowo, 2006).

Produksi bawang merah di Indonesia pada tahun 2013 sebesar 42.791 ton, dibandingkan tahun 2012, produksi meningkat sebesar 6.953 ton. Peningkatan ini disebabkan oleh meningkatnya luas panen sebesar 474 hektar dan peningkatan produktivitas sebesar 0,56 ton $\mathrm{ha}^{-1}$ dibandingkan tahun 2012. Produksi bawang merah di Provinsi Aceh pada tahun 2013 sebesar 3.710 ton mengalami penurunan 
dibandingkan pada tahun 2012 sebesar 4.385 ton (Badan Pusat Statistik, 2014).

Upaya peningkatan produksi tanaman bawang merah dapat dilakukan, antara lain dengan pengaturan jarak tanam yang tepat dan perlakuan pemupukan. Pada tanah yang subur, jarak tanam dapat dibuat relatif rapat dibandingkan pada tanah yang kurang subur. Jarak tanam yang biasa digunakan untuk tanaman bawang merah adalah $20 \mathrm{~cm} \times 15 \mathrm{~cm}$ atau $20 \mathrm{~cm} \times 20 \mathrm{~cm}$, tergantung pada jenis dan kualitas kesuburan tanahnya (Rukmana, 1994).

Pegaturan jarak tanam bertujuan memberi ruang tumbuh pada tiap-tiap tanaman agar tumbuh dengan baik. Jarak tanam mempengaruhi penggunaan cahaya, persaingan diantara tanaman dalam penggunaan air dan unsur hara sehingga akan mempengaruhi produksi tanaman. Pada kerapatan yang rendah tanaman kurang berkompetisi dengan tanaman lain, sehingga penampilan individu tanaman lebih baik. Sebaliknya pada kerapatan tinggi, tingkat kompetisi diantara tanaman terhadap cahaya, air dan unsur hara semakin ketat sehingga tanaman dapat terhambat pertumbuhannya (Hidayat, 2008).

Selain penggunaan jarak tanam yang tepat, penggunaan pupuk organik juga sangat mempengaruhi pertumbuhan dan hasil tanaman bawang merah. Pemupukan dapat dilakukan melalui tanah ataupun daun. Penggunaan pupuk organik terus meningkat untuk mewujudkan pertanian organik yaitu pertanian yang ramah lingkungan. Salah satu cara yang ditempuh agar tujuan tersebut dapat tercapai yaitu dilakukan pemupukan dengan menggunakan pupuk organik seperti pupuk kandang dan pupuk organik cair (Sarief, 1986).

Penelitian ini bertujuan untuk mengetahui pengaruh jarak tanam dan dosis pupuk kandang yang tepat, untuk pertumbuhan dan hasil tanaman bawang merah yang maksimal serta interaksi antara kedua faktor tersebut.

\section{METODE}

Penelitian ini dilaksanakan di Stasiun Penelitian Pertanian (University Farm), Substasiun Hortikultura Organik Darussalam, Banda Aceh. Penelitian ini dilaksanakan dari bulan Maret 2016 sampai dengan Mei 2016.

Bahan dan Alat

Bahan yang digunakan adalah umbi bawang merah varietas Bima Brebes (deskripsi pada lampiran 29) yang diperoleh dari Toko Istana Bawang, Pasar Peunayong sebanyak $2 \mathrm{~kg}$. Jumlah umbi yang digunakan sebanyak 550 umbi, untuk perlakuan sebanyak 480 umbi dan 70 umbi untuk penyulaman. Pupuk yang digunakan adalah pupuk kandang berupa kotoran sapi yang sudah terdekomposisi sempurna sebanyak $36 \mathrm{~kg}$. Alat-alat yang digunakan dalam penelitian ini antara lain cangkul, garu, meteran, gembor, selang, mesin sanyo, pisau, timbangan digital, papan nama, tali plastik, kamera serta alat tulis menulis.

Rancangan Penelitian

Rancangan percobaan yang digunakan dalam penelitian ini adalah Rancangan Acak Kelompok (RAK) pola faktorial $2 \times 4$ dengan 3 ulangan.

Ada dua faktor perlakuan yang diteliti yaitu:

(1) Faktor jarak tanam (J) terdiri atas :

$\mathrm{J}_{1}=20 \mathrm{~cm} \times 15 \mathrm{~cm}$

$\mathrm{J}_{2}=20 \mathrm{~cm} \times 25 \mathrm{~cm}$

(2) Faktor dosis pupuk kandang (D) terdiri atas :

$\mathrm{D}_{0}=$ Tanpa pupuk kandang (kontrol)

$\mathrm{D}_{1}=10$ ton $\mathrm{ha}^{-1} \approx 1 \mathrm{~kg} /$ bedeng

$\mathrm{D}_{2}=20$ ton $\mathrm{ha}^{-1} \approx 2 \mathrm{~kg} /$ bedeng

$\mathrm{D}_{3}=30$ ton ha ${ }^{-1} \approx 3 \mathrm{~kg} /$ bedeng 


\section{HASIL DAN PEMBAHASAN}

Pengaruh jarak tanam

Hasil uji $\mathrm{F}$ pada analisis ragam menunjukkan bahwa jarak tanam berpengaruh sangat nyata terhadap berat berangkasan basah per bedeng dan berat kering umbi per bedeng. Berpengaruh nyata terhadap tinggi tanaman umur 30 HST, berat berangkasan kering per bedeng.
Berpengaruh tidak nyata terhadap tinggi tanaman umur 15 dan 45 HST, jumlah daun umur 15, 30 dan 45 HST, jumlah anakan per rumpun, jumlah umbi per rumpun, berat berangkasan basah per rumpun, berat berangkasan kering per rumpun, berat kering umbi per rumpun, potensi hasil (Tabel 1).

Tabel 1. Pengaruh jarak tanam terhadap parameter pertumbuhan dan hasil bawang merah

\begin{tabular}{|c|c|c|c|c|}
\hline \multirow{2}{*}{ Parameter } & & \multicolumn{2}{|c|}{ Jarak Tanam $(\mathrm{cm} \mathrm{x} \mathrm{cm)}$} & \multirow[t]{2}{*}{$\begin{array}{l}\text { BNJ } \\
0,05 \\
\end{array}$} \\
\hline & & $20 \times 15$ & $20 \times 25$ & \\
\hline \multirow{4}{*}{ Tinggi Tanaman $(\mathrm{cm})$} & $15 \mathrm{HST}$ & 11,25 & 11,57 & - \\
\hline & $30 \mathrm{HST}$ & $22,85 \mathrm{~b}$ & $20,56 \mathrm{a}$ & 0,75 \\
\hline & $45 \mathrm{HST}$ & 24,63 & 22,75 & - \\
\hline & 15 HST & 8,68 & 8,83 & - \\
\hline \multirow{2}{*}{ Jumlah Daun (helai) } & $30 \mathrm{HST}$ & 14,22 & 13,54 & - \\
\hline & 45 HST & 16,33 & 15,75 & - \\
\hline Jumlah Anakan per Rumpun & $55 \mathrm{HST}$ & 4,52 & 3,91 & - \\
\hline Jumlah Umbi per Rumpun & $55 \mathrm{HST}$ & 6,62 & 5,89 & - \\
\hline $\begin{array}{l}\text { Berat Berangkasan Basah per } \\
\text { Rumpun }\end{array}$ & $55 \mathrm{HST}$ & 15,31 & 13,85 & - \\
\hline $\begin{array}{l}\text { Berat Berangkasan Kering per } \\
\text { Rumpun }\end{array}$ & $55 \mathrm{HST}$ & 12,80 & 11,30 & - \\
\hline $\begin{array}{l}\text { Berat Berangkasan Basah per } \\
\text { Bedeng }\end{array}$ & $55 \mathrm{HST}$ & $329,58 \mathrm{~b}$ & 200,41 a & 21,25 \\
\hline $\begin{array}{l}\text { Berat Berangkasan Kering per } \\
\text { Bedeng }\end{array}$ & $55 \mathrm{HST}$ & $240,70 \mathrm{~b}$ & $154,84 \mathrm{a}$ & 23,05 \\
\hline Berat Kering Umbi per Rumpun & 55 HST & 12,12 & 10,71 & - \\
\hline Berat Kering Umbi per Bedeng & $55 \mathrm{HST}$ & $234,47 \mathrm{~b}$ & $141,66 \mathrm{a}$ & 15,89 \\
\hline Potensi Hasil & $55 \mathrm{HST}$ & 4,04 & 2,14 & - \\
\hline
\end{tabular}

Hasil penelitian menunjukkan bahwa jarak tanam berpengaruh sangat nyata terhadap berat berangkasan basah per bedeng dan berat kering umbi per bedeng, berpengaruh nyata terhadap tinggi tanaman umur 30 HST, berat berangkasan kering per bedeng dan potensi hasil. Berpengaruh tidak nyata terhadap tinggi tanaman umur 15 dan 45 HST, jumlah daun umur 15, 30 dan 45 HST, jumlah anakan per rumpun, jumlah umbi per rumpun, berat berangkasan basah per rumpun, berat berangkasan kering per rumpun, berat kering umbi per rumpun. Pertumbuhan dan hasil yang terbaik terdapat pada jarak tanam $20 \mathrm{~cm} \times 15 \mathrm{~cm}$ yang diamati pada peubah, hal ini dikarenakan jarak tanam yang ideal menyebabkan tanaman tidak saling memperebutkan unsur hara yang ada dan juga dapat dengan mudah melakukan pengendalian gulma ataupun organisme pengganggu tanaman lainnya.

Hasil penelitian Hidayat dan Rosliani (2003) menyatakan bahwa jarak 
tanam optimal untuk produksi umbi bawang merah asal benih konvensional (4-5 g per umbi) adalah $10 \times 20 \mathrm{~cm}$ atau $15 \times 20 \mathrm{~cm}$. Jarak tanam juga didukung oleh faktor kesuburan tanah, dimana semakin subur tanah semakin kecil pula jarak tanam yang digunakan sehingga dapat memaksimalkan luas lahan, hal ini sejalan dengan Jumin (2002) yang menyatakan untuk mendapatkan jarak tanam yang tepat beberapa hal yang harus diperhatikan diantaranya kesuburan tanah. Semakin subur tanah maka jarak tanam diperkecil.
Pengaruh dosis pupuk kandang

Hasil uji $F$ pada analisis ragam menunjukkan bahwa pengaruh dosis pupuk kandang berpengaruh tidak nyata pada tinggi tanaman umur 15, 30 dan 45 HST, jumlah daun umur 15,30 dan 45 HST, jumlah anakan per rumpun, jumlah umbi per rumpun, berat berangkasan basah per rumpun, berat berangkasan kering per rumpun, berat berangkasan basah per bedeng, berat berangkasan kering per bedeng, berat kering umbi per rumpun, berat kering umbi per bedeng, potensi hasil (Tabel 2).

Tabel 2. Pengaruh dosis pupuk kandang terhadap parameter pertumbuhan dan hasil bawang merah

\begin{tabular}{|c|c|c|c|c|c|c|}
\hline \multirow[t]{2}{*}{ Parameter } & & \multicolumn{4}{|c|}{$\begin{array}{l}\text { Dosis Pupuk Kandang } \\
\quad\left(\text { ton } \mathrm{ha}^{-1} \text { ) }\right.\end{array}$} & \multirow{2}{*}{$\begin{array}{l}\text { BNJ } \\
0,05\end{array}$} \\
\hline & & 0 & 10 & 20 & 30 & \\
\hline \multirow{4}{*}{ Tinggi Tanaman $(\mathrm{cm})$} & $15 \mathrm{HST}$ & 7,47 & 7,13 & 7,83 & 8,00 & - \\
\hline & $30 \mathrm{HST}$ & 14,75 & 14,01 & 14,38 & 14,73 & - \\
\hline & 45 HST & 15,94 & 15,39 & 15,68 & 16,15 & - \\
\hline & $15 \mathrm{HST}$ & 6,36 & 5,47 & 5,30 & 6,22 & - \\
\hline \multirow[t]{2}{*}{ Jumlah Daun (helai) } & $30 \mathrm{HST}$ & 10,36 & 8,50 & 8,91 & 9,25 & - \\
\hline & 45 HST & 11,77 & 9,94 & 10,33 & 10,72 & - \\
\hline Jumlah Anakan per Rumpun & $55 \mathrm{HST}$ & 3,08 & 2,63 & 2,61 & 2,91 & - \\
\hline Jumlah Umbi per Rumpun & 55 HST & 4,38 & 4,19 & 3,86 & 4,25 & - \\
\hline $\begin{array}{l}\text { Berat Berangkasan Basah per } \\
\text { Rumpun }(\mathrm{g})\end{array}$ & $55 \mathrm{HST}$ & 8,88 & 9,86 & 9,72 & 10,41 & - \\
\hline $\begin{array}{l}\text { Berat Berangkasan Kering per } \\
\text { Rumpun }(\mathrm{g})\end{array}$ & $55 \mathrm{HST}$ & 7,41 & 8,12 & 7,88 & 8,72 & - \\
\hline $\begin{array}{l}\text { Berat Berangkasan Basah per } \\
\text { Bedeng }(\mathrm{g})\end{array}$ & $55 \mathrm{HST}$ & 167,22 & 164,44 & 205,00 & 170,00 & - \\
\hline $\begin{array}{l}\text { Berat Berangkasan Kering per } \\
\text { Bedeng }(\mathrm{g})\end{array}$ & $55 \mathrm{HST}$ & 103,92 & 126,51 & 162,98 & 133,97 & - \\
\hline $\begin{array}{l}\text { Berat Kering Umbi per } \\
\text { Rumpun }(\mathrm{g})\end{array}$ & $55 \mathrm{HST}$ & 7,11 & 7,62 & 7,46 & 8,24 & - \\
\hline $\begin{array}{l}\text { Berat Kering Umbi per Bedeng } \\
(\mathrm{g})\end{array}$ & $55 \mathrm{HST}$ & 113,58 & 113,61 & 153,12 & 121,20 & - \\
\hline Potensi Hasil & 55 HST & 2,37 & 2,54 & 2,48 & 2,74 & - \\
\hline
\end{tabular}

Hasil uji $\mathrm{F}$ pada analisis ragam menunjukkan bahwa tidak terdapat interaksi yang nyata antara perlakuan jarak tanam dan dosis pupuk kandang terhadap semua peubah pertumbuhan dan hasil tanaman bawang merah yang diamati. Hal ini berarti bahwa perbedaan pertumbuhan dan hasil tanaman bawang merah akibat perbedaan 
jarak tanam tidak tergantung pada dosis pupuk kandang, begitu juga sebaliknya.

Hasil penelitian menunjukkan bahwa perlakuan dosis pupuk kandang berpengaruh tidak nyata terhadap pertumbuhan dan hasil tanaman bawang merah yang diamati pada semua peubah. Dari berbagai perlakuan dosis pupuk kandang yang dicobakan, ternyata pada dosis 20 ton ha ${ }^{-1}$ yang dapat memberikan hasil yang lebih baik kemudian disusul oleh perlakuan pupuk kandang pada dosis 30 ton $\mathrm{ha}^{-1}$ dan perlakuan pupuk kandang pada dosis kontrol, hasil yang terendah dijumpai pada perlakuan pupuk kandang pada dosis 10 ton $\mathrm{ha}^{-1}$.

Lingga dan Marsono (2006) menyatakan bahwa, dosis pemberian pupuk sangat penting diperhatikan karena berhubungan dengan kemampuan pupuk tersebut dalam mempengaruhi tanah. Suseno (1974) menambahkan bahwa, tanaman yang kekurangan unsur hara akan terganggu proses metabolismenya sehingga pertumbuhan tanaman menjadi terhambat.

Pengaruh interaksi antara perlakuan jarak tanam dan dosis pupuk kandang

Hasil penelitian menunjukkan bahwa tidak terdapat interaksi yang nyata antara perlakuan jarak tanam dan dosis pupuk kandang terhadap semua peubah yang diamati. Hal ini menunjukkan bahwa respon tanaman bawang merah akibat perlakuan jarak tanam tidak berpengaruh dengan perlakuan dosis pupuk kandang, begitu juga sebaliknya.

\section{KESIMPULAN}

Jarak tanam berpengaruh sangat nyata terhadap berat basah berangkasan per bedeng dan berat kering umbi per bedeng, berpengaruh nyata pada tinggi tanaman umur 30 HST dan berat kering berangkasan per bedeng. Pertumbuhan dan hasil terbaik dijumpai pada jarak tanam $20 \mathrm{~cm} \times 15 \mathrm{~cm}$. Dosis pupuk kandang berpengaruh tidak nyata terhadap semua peubah yang diamati. Pertumbuhan dan hasil tanaman bawang merah cenderung lebih baik pada dosis pupuk kandang 20 ton $\mathrm{ha}^{-1}$. Terdapat interaksi yang tidak nyata antara perlakuan jarak tanam dengan dosis pupuk kandang terhadap pertumbuhan dan hasil tanaman bawang merah.

\section{DAFTAR PUSTAKA}

Badan Pusat Statistik (BPS). 2014. Data Produksi Bawang Merah. Diakses dari http://www.bps.go.id. Badan Pusat Statistik. Provinsi Aceh. [Diakses pada 27 Juni 2016 ].

Hidayat A dan Rosliani R. 2003. Pengaruh jarak tanam dan ukuran umbi bibit bawang merah terhadap hasil dan distribusi ukuran umbi bawang merah: Laporan hasil penelitian. Balai Penelitian Tanaman Sayuran. Lembang.

Hidayat N. 2008. Pertumbuhandan Produksi Kacang Tanah (Arachis hypogea L.) Varietas Lokal Madura pada Berbagai Jarak Tanam dan Dosis Pupuk Fosfor. http://pertanian trunojoyo.ac.id/wpcontent. [Diakses pada 12 Juni 2016].

Jumin HB. 2002. Dasar-dasar Agronomi. Raja Grafindo Persada. Jakarta.

Lingga $\mathrm{P}$ dan Marsono. 2006. Petunjuk Penggunaan Pupuk. Penebar Swadaya. Jakarta.

Putrasamedja S. dan Suwandi. 1996. Bawang Merah di Indonesia. Balai Penelitian Tanaman Sayuran. Bandung.

Rukmana R. 1994. Bertanam Selada dan Andewi. Kanisius. Yogyakarta.

Sarief ES. 1986. Kesuburan dan Pemupukan Tanah Pertanian. Pustaka Buana. Bandung.

Sumarni N dan Hidayat A. 2005. Panduan Teknis Budidaya Bawang Merah. Balai Penelitian Tanaman Sayuran. Bandung. 
Suseno H. 1974. Fisiologi Tumbuhan Metabolisme Dasar. Departemen Agronomi IPB. Bogor.

Wibowo S. 2006. Budidaya Bawang (Bawang Putih, Bawang Merah dan
Bawang Bombay). Penebar Swadaya. Jakarta. 